\title{
Hybrid Method of First Come First Served and Priority Queue for Queue System in Hospital
}

\author{
D. Jayus Nor Salim \\ Department of Information System \\ Diponegoro University \\ Semarang, Indonesia
}

\author{
Jatmiko Endro Suseno \\ Department of Physics \\ Diponegoro University \\ Semarang, Indonesia
}

\author{
Oky Dwi Nurhayati \\ Department of Informatic \\ Diponegoro University \\ Semarang, Indonesia
}

\begin{abstract}
People must have been queuing up at service places like banks, hospitals, etc. For now most of the queues are still conventional. The queue is done manually, the customer takes the queue number and waits until it's his turn. In computer systems people are familiar with queuing theory, such as FIFO, LIFO, PQ, etc. Sometimes, it combines several queue theories to execute the program. This study, queuing system will adopt from queue theory which is used by computer system. Hybrid system from FCFS and PQ will serve customers according to their needs. This study was conducted at the service place of one of the government hospital in Surakarta city. The sample queue data will be analyzed and compared when using the conventional queue and after using this queue system. This queuing system utilizes cloud technology to be accessible anywhere and display results in real time. The average waiting time in the hospital service using a conventional queue system is $2-5$ hours, while using this system is $10-30$ minutes.
\end{abstract}

\section{General Terms}

Cloud Queue System

\section{Keywords}

Information system, Queue system, Scheduling algorithm, FCFS, Priority queue, Cloud computing

\section{INTRODUCTION}

People cannot be separated from activities that require queues. They can find examples of queue when queuing at the bank service, hospital, supermarket cashier, etc. Many people complained about the queue is too long, so much time wasted. The time spent in queuing should be used for other more productive activities, so their time can be used more efficiently and effectively [1].

Queue is a process associated with the arrival of customers / customers in a place of service, waiting in the queue line when there is a stack of customers who have not served [2]. There are many queuing systems used by the company. Most of the queues are still conventional. The queue is done manually, the customers takes the queue number and waits until the queue number is their turn. The conventional queues is similar with the method queue system in the system of computer, that is first come first served (FCFS) method.

The first requesting process will be served first, it is called FCFS. Meanwhile, the requesting process with priority number, it is called priority queue (PQ). For example the smaller of priority number is more prioritized [3]. They are one of the methods contained in the Central Processing Unit (CPU) scheduling algorithm on a computer system. This research will apply the queuing model used by the CPU into a human queue. There are some differences between queues that are applied to the CPU with queues for humans. The difference is in the object of research. Queue in the CPU is a queue of execution of commands. It is performed by the machine and done in micro seconds even smaller, while the queue in humans is a queue of services that involve humans as objects and done in minutes even hours [4]. Queues in humans also consider the psychological impacts that are naturally possessed by humans. Therefore, the scheduling algorithm to be applied in this study will be modified according to the research needs to achieve the research objectives

This research will combines FCFS and PQ method and the system run online. This system will be built on a web platform using cloud computing technology. This technology utilizes the Internet as a data transmission. It will be accessible anywhere and display results in real time Customers can retrieve the queue number and monitor the ongoing queue number which are being served. Customers arrive when the queue number is approaching time served. It is expected that the time spent by Customers to queue can be used to do more productive work so that their time is more efficient and useful [5].

\section{RELATED WORK}

Takagi's research was conducted on hospital services. By using a method of estimating the length of treatment for each patient, the patient can only find out when the hospitalized room will be empty and usable. By applying a multi-channel queue model with server in the form of room care and patient visitors. Visitors will be separated by type of disease to be served by different servers according to the type of disease.

Nanjing University of Science and Technology conducts research on queues at bank service centers using the Bussines Process Reengineering (BPR) method. BPR performs the optimization of the server work to serve the visitor. Optimization is done in the BPR that is by determining the number of servers and destination servers are different for each visitor. Visitors will be served by different servers based on the type of service that visitors will want [6].

Research on scheduling theory is used to optimize the management of a bank. This study utilizes cellular phone technology to optimize queues and improve service productivity [7].

Research on arrival and departure of trains. Arrival and departure of the train has actually been done in accordance with his schedule, but one day can happen a train is required to come or depart first. This is done by delaying the train schedule to be inserted [8].

\section{RESEARCH METHODOLOGY 3.1 Scheduling Algorithm}

Scheduling sets the number of resources to work optimally (not many unemployed and not many queues). CPU scheduling is the process to make a queue is ready to be 
executed by the CPU [9].

\subsection{Queue Structure}

This research use queue structure multi channel single phase. There are 2 facilities or more is done in same time [10].

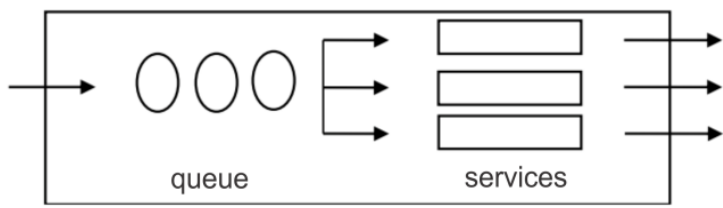

Fig 1 : Queue structured : multi channel single phase

\subsection{First Come First Served}

The earliest process order will be served first. This FCFS method is a common method used to solve public queuing problems [11].

Table 1. FCFS Process

\begin{tabular}{|l|l|}
\hline Process & Burst Time \\
\hline P1 & 24 \\
\hline P2 & 3 \\
\hline P3 & 3 \\
\hline
\end{tabular}

by FCFS, process will be served like fig. 2

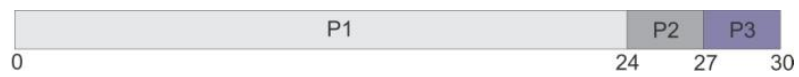

Fig 2 : FCFS Process

\subsection{Kendall Notation}

To understand the characteristics of a queuing system used Kendall Notation. Kendall notation is used to explain how the queue system that reviewed works and is modeled [12].

Step I shows the variable of data type

$\lambda=\frac{1}{T 1 / N}$

$\mu=\frac{1}{T 2 / N}$

$\lambda=$ customers arrival rate

$\mu=$ service level

$\mathrm{T} 1=$ total time between arrivals

$\mathrm{T} 2=$ total customers service time

$\mathrm{N}=$ total customers

Step II determines the value of unemployment opportunity $\left(\mathrm{P}_{0}\right)$

$$
\begin{aligned}
& P_{0}=\left(\sum_{n=0}^{c=1} \frac{\left(\frac{\lambda}{\mu}\right)^{n}}{n !}+\right. \\
& \left.\frac{\left(\frac{\lambda}{\mu}\right)^{c}}{c !\left(1-\left(\frac{\lambda}{c} \cdot \mu\right)\right)}\right)^{-1}
\end{aligned}
$$

Information:

$\mathrm{P}_{0}=$ probability of idle time

$\lambda=$ customers arrival rate $\mu=$ service level

$c=$ number of service facilities

Step III determines the $\mathrm{L}_{\mathrm{q}}$, the average number of customers in the queue.

$L_{q}=\frac{\left(\frac{\lambda}{\mu}\right)^{c} \cdot\left(\frac{\lambda}{c . \mu}\right)}{c !\left(1-\left(\frac{\lambda}{c . \mu}\right)\right)^{2}} P_{0}$

Information:

$\mathrm{L}_{\mathrm{q}}=$ average number of customers in the queue

$\mathrm{P}_{0}=$ probability of idle time

$\lambda=$ customer arrival rate

$\mu=$ service level

$\mathrm{c}=$ number of service facilities

Step IV determines $L_{s}$, the average number of customers in the system.

$L_{s}=L_{q}+\frac{\lambda}{\mu}$

Information:

$\mathrm{L}_{\mathrm{s}}=$ average number of customers in the system

$\mathrm{L}_{\mathrm{s}}=$ average number of customers in the queue

$\lambda=$ customer arrival rate

$\mu=$ service level

Step $\mathrm{V}$ determines $\mathrm{W}_{\mathrm{q}}$, the average customers time in the queue.

$W_{q}=\frac{L_{q}}{\lambda}$

Information :

$\mathrm{W}_{\mathrm{q}}=$ average customers time in queue

$\mathrm{L}_{\mathrm{q}}=$ average number of customers in the queue

$\lambda=$ customer arrival rate

$\mu=$ service level

Step VI specifies $\mathrm{W}_{\mathrm{s}}$, the average customers time in the system.

$W_{s}=W_{q}+\frac{1}{\mu}$

Information :

$\mathrm{W}_{\mathrm{s}}=$ average customers time in the system

$\mathrm{W}_{\mathrm{q}}=$ average customers time in queue

$\mu \quad=$ service level

\subsection{Priority Queue}

The Priority Queue (PQ) algorithm is part of the Shortest Job First (SJF) in scheduling algorithm. SJF is used when CPU processes which have the shortest time will get priority. If two or more processes have the same time then the FCFS algorithm is used to solve the problem. PQ can be allocated to processes with the highest priority. For the same priority done with FCFS [13]. 


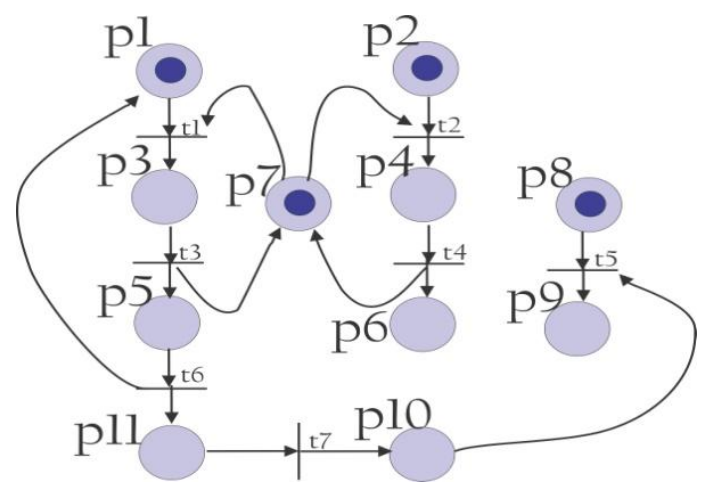

Fig 3 : PQ Process

\subsection{Hybrid FCFS + PQ}

Hybrid FCFS + PQ algorithm is a hybrid of first come first served and priority queue methods of scheduling algorithm. In this, people in line choose the type of queue, FCFS or PQ. If they choose FCFS, they can get the fastest time of waiting time in line. If they choose PQ, they can order the time as they want. Then the PQ will interrupt or insert the queue. If there is more than one customers choose the same time, then FCFS is executed [14]. For example interruption process in CPU shown on fig.4.

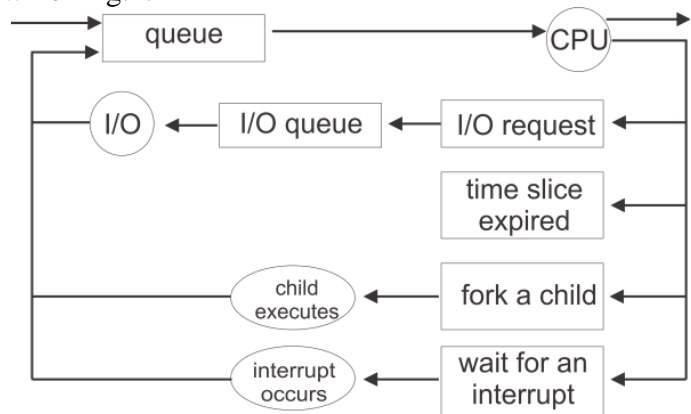

Fig 4 : Interuption or Insertion Process on CPU

\subsection{Cloud Computing}

Cloud or the internet is an innovation technology platform to provide users with high-scale services. The use of cloud can be controlled remotely because this technology uses the internet as a media access. Therefore a system should be built using this technology so users can use the system wherever and whenever [15].

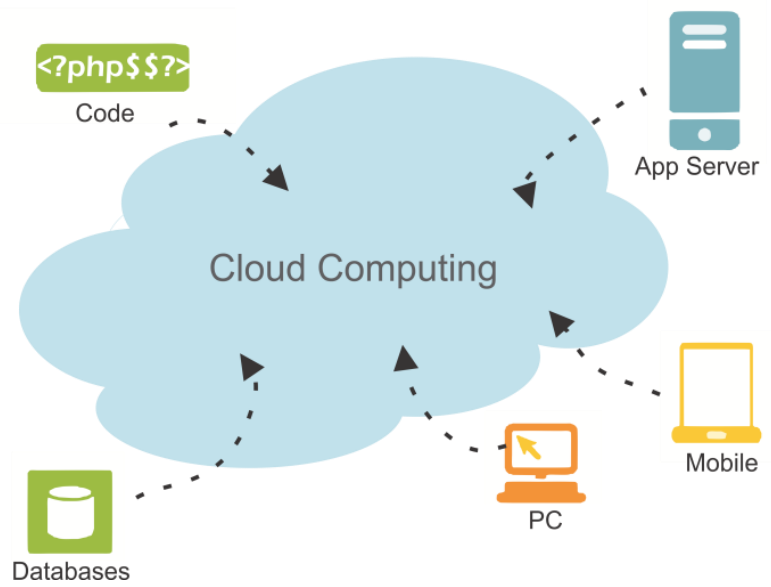

Fig 3 : Cloud Computing Scheme

\section{DESIGN OF RESEARCH}

\subsection{Material and Tools}

The tools and materials used in this research are some places where there is a queue process in there. This research especially do the sample in hospital in Surakarta City. This research combine queue system before and after the new system applied. The system process the data using FCFS and PQ combination method. The system is made in web platform and online.

\subsection{Research Procedure}

Research procedure can be shown on fig. 4 .

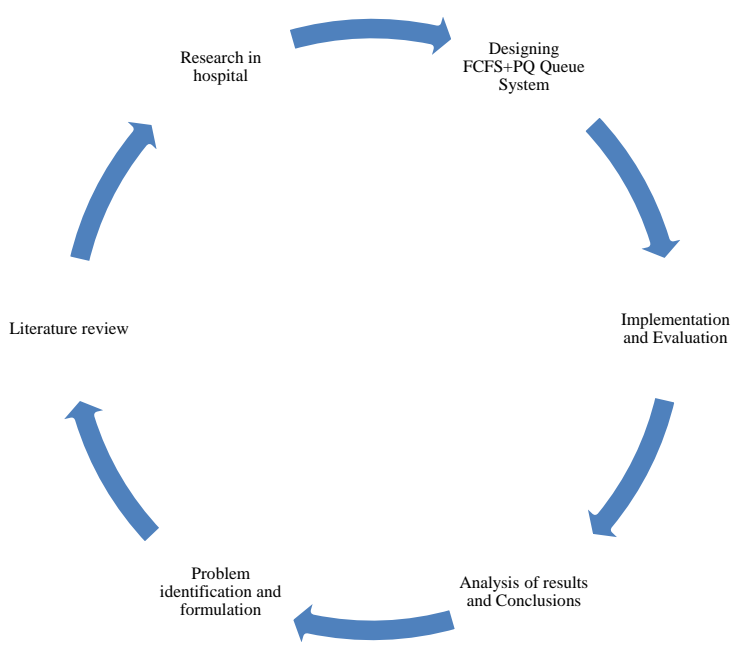

Fig 4 : Research Procedure

After observation, the data shown in table 2

\begin{tabular}{|c|c|c|c|}
\hline $\begin{array}{l}\text { Customer } \\
\text { Number }\end{array}$ & $\begin{array}{l}\text { Arrival } \\
\text { Time }\end{array}$ & $\begin{array}{l}\text { Start Time } \\
\text { Served }\end{array}$ & $\begin{array}{l}\text { Finished } \\
\text { Time Served }\end{array}$ \\
\hline 1 & 05.00 & 08.10 & 08.20 \\
\hline 2 & 05.05 & 08.20 & 08.32 \\
\hline 3 & 05.08 & 08.32 & 08.40 \\
\hline 4 & 05.10 & 08.43 & 08.55 \\
\hline 5 & 05.15 & 08.55 & 09.05 \\
\hline 6 & 05.18 & 09.10 & 09.20 \\
\hline 7 & 05.25 & 09.20 & 09.32 \\
\hline 8 & 05.30 & 09.32 & 09.42 \\
\hline 9 & 05.45 & 09.45 & 09.55 \\
\hline 10 & 06.10 & 09.55 & 10.10 \\
\hline 11 & 06.30 & 10.20 & 10.28 \\
\hline 12 & 06.40 & 10.28 & 10.40 \\
\hline 13 & 07.00 & 10.40 & 10.55 \\
\hline 14 & 07.25 & 10.55 & 11.05 \\
\hline 15 & 07.30 & 11.10 & 11.20 \\
\hline
\end{tabular}




\begin{tabular}{|l|l|l|l|}
\hline 16 & 08.00 & 13.00 & 13.15 \\
\hline 17 & 08.10 & 13.15 & 13.23 \\
\hline 18 & 08.30 & 13.25 & 13.40 \\
\hline 19 & 08.50 & 13.40 & 13.50 \\
\hline 20 & 09.00 & 13.50 & 14.05 \\
\hline
\end{tabular}

Then, analyzing Kendall Notation

\subsubsection{Shows The Variable of Data Type}

The process of determining the data type variable is shown by the following formula.

Counting customer arrivals:

$$
\begin{aligned}
\lambda & =\frac{1}{T 1 / N} \\
\lambda & =\frac{1}{240 / 20} \\
\lambda & =\frac{1}{12} \\
\lambda & =0.08
\end{aligned}
$$

Calculating service levels:

$$
\begin{aligned}
\mu & =\frac{1}{T 2 / N} \\
\mu & =\frac{1}{227 / 20} \\
\mu & =\frac{1}{11.35} \\
\mu & =0.09
\end{aligned}
$$

4.2.2 Determines The Value of Unemployment Opportunity $\left(P_{0}\right)$

After getting the value of the variables of the customer arrival rate and service level, the next step is to determine the value of unemployment opportunities:

$$
\begin{aligned}
& P_{0}=\left(\sum_{n=0}^{c=1} \frac{\left(\frac{\lambda}{\mu}\right)^{n}}{n !}+\frac{\left(\frac{\lambda}{\mu}\right)^{c}}{c !\left(1-\left(\frac{\lambda}{c} \cdot \mu\right)\right.}\right)^{-1} \\
& P_{0}=\left(\frac{\left(\frac{0.08}{0.09}\right)^{0}}{0 !}+\left(\frac{\left(\frac{0.08}{0.09}\right)^{1}}{1 !\left(1-\frac{0.08}{1(0.09)}\right)}\right)^{-1}\right. \\
& P_{0}=\left(\frac{1}{1}+\frac{0.89}{1 .(1-0.89)}\right)^{-1} \\
& P_{0}=\left(1+\frac{0.89}{1(0.11)}\right)^{-1} \\
& P_{0}=\left(1+\frac{0.89}{0.11}\right)^{-1} \\
& P_{0}=(1+8.09)^{-1} \\
& P_{0}=(9.09)^{-1} \\
& P_{0}=\frac{1}{9.09} \\
& P_{0}=\frac{1}{9.09} \\
& P_{0}=0.11 \text { or } 11 \%
\end{aligned}
$$

In the case of queuing at the hospital, the number of service facilities can be more than one, but the number of service facilities more than one is usually found in the registration service, while this research takes the case on the service in special poly. Special Poly usually there is only one doctor / service facility in each poly. So, in this case the value of $\mathrm{c}=1$.

\subsubsection{Determining Average Number of Customers} in Queue

After getting the value of the idle time opportunity on the queue, the next step is to determine the average number of customers in the queue:

$$
\begin{aligned}
L_{q} & =\frac{\left(\frac{\lambda}{\mu}\right)^{c} \cdot\left(\frac{\lambda}{c \cdot \mu}\right)}{c !\left(1-\left(\frac{\lambda}{c \cdot \mu}\right)\right)^{2}} P_{0} \\
L_{q} & =\frac{\left(\frac{0.08}{0.09}\right)^{1} \cdot\left(\frac{0.08}{1 \cdot(0.09)}\right)}{1 !\left(1-\left(\frac{0.08}{1 \cdot(0.09)}\right)\right)^{2}} \cdot(0.11) \\
L_{q} & =\frac{(0.89) \cdot(0.89)}{1 \cdot(1-(0.89))^{2}} \cdot(0.11) \\
L_{q} & =\frac{0.7921}{(0.11)^{2}} \cdot(0.11) \\
L_{q} & =\frac{0.7921}{0.0121} \cdot(0.11) \\
L_{q} & =\frac{0.7921}{0.0121} \cdot(0.11) \\
L_{q} & =(65.46) \cdot(0.11) \\
L_{q} & =7.2
\end{aligned}
$$

The value of $\mathrm{Lq}$ is 7.2 , rounded to 7 . So the average number of customers in the queue is 7 customers in the queue.

\subsubsection{Determining Average Number of Customers in The System}

After getting the average number of customers in the queue, the next step is to determine the average number of customers in the system:

$$
\begin{aligned}
& L_{s}=L_{q}+\frac{\lambda}{\mu} \\
& L_{s}=7.2+\frac{0.08}{0.09} \\
& L_{s}=7.2+0.89 \\
& L_{s}=8.09
\end{aligned}
$$

The value of Ls is 8.09 , rounded to 8 . So the average number of customers in the system is 8 customers in the system.

\subsubsection{Determining Average Time Customer in Queue}

After getting the value of the average number of customers in the system, the next step is to determine the average customer time in the queue:

$$
\begin{aligned}
& W_{q}=\frac{L_{q}}{\lambda} \\
& W_{q}=\frac{7.2}{0.08} \\
& W_{q}=90
\end{aligned}
$$

The $\mathrm{Wq}$ value is 90 . So the average customer time in the queue is 90 minutes / customer.

\subsubsection{Determining Average Time Customer in System}

After getting the average customer time value in the queue, the next step is to determine the average time the customer is in the system: 


$$
\begin{aligned}
& W_{s}=W_{q}+\frac{1}{\mu} \\
& W_{s}=90+\frac{1}{0.09} \\
& W_{s}=90+11.11 \\
& W_{s}=101.11
\end{aligned}
$$

The value of Ws is 101.11. So the average customer time in the system is 101.11 minutes / customer.

\subsection{Physical Data Model \\ 4.3.1 Flowchart}

Flowchart of the user data shown on fig. 5.

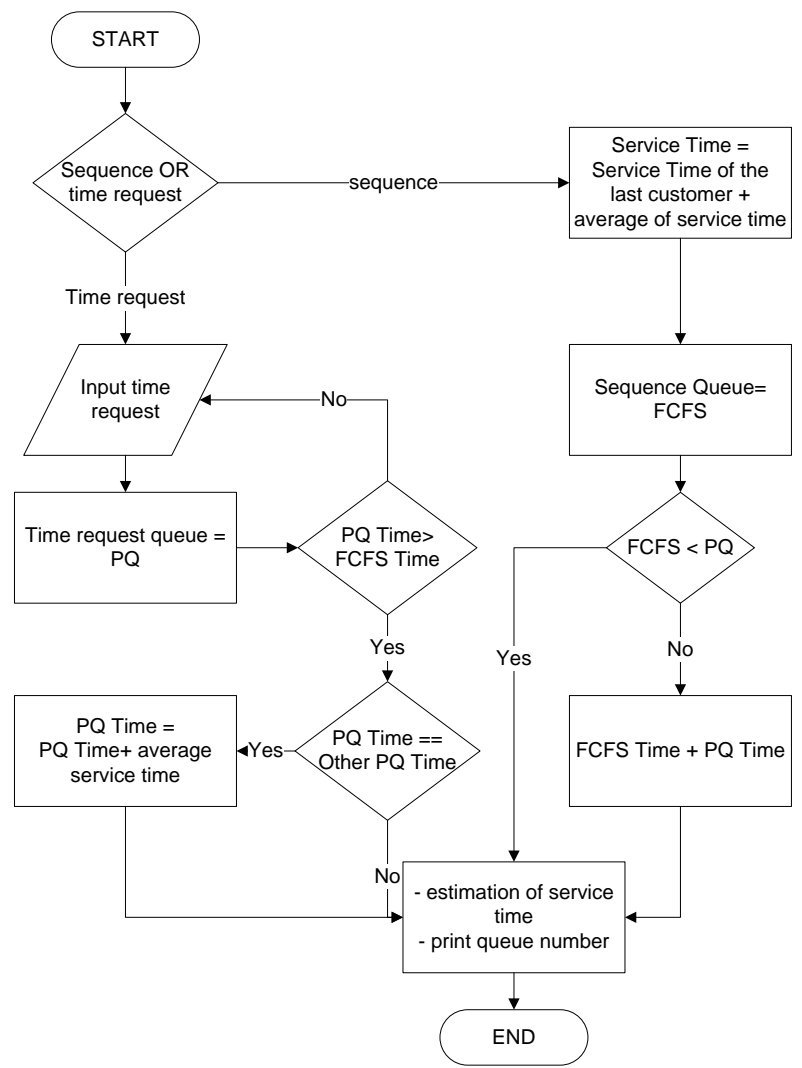

Fig 5 : Flowchart System

Customers can choose type of queue, they are sequence queue or time request. Sequence queue is FCFS, who comes first will served first. So, if customers would to choose the fastest queue can choose this sequence queue. Other choices is time request, customers can order served time. If there is request time in same time, then FCFS execute them.

\subsubsection{Databases}

The databases is needed to store the data, which shown below.

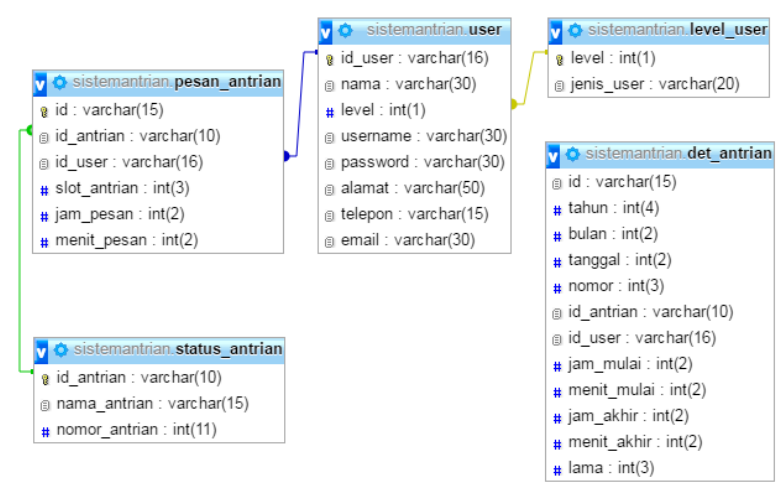

Fig 6 : Databases Structure

Fig. 6 is the structure database of the system. The data of customers are saved in store media to be processed and analyzed.

\subsubsection{Interfaces}

Interfaces of the system shown on fig. 7.

\subsubsection{Home Page}

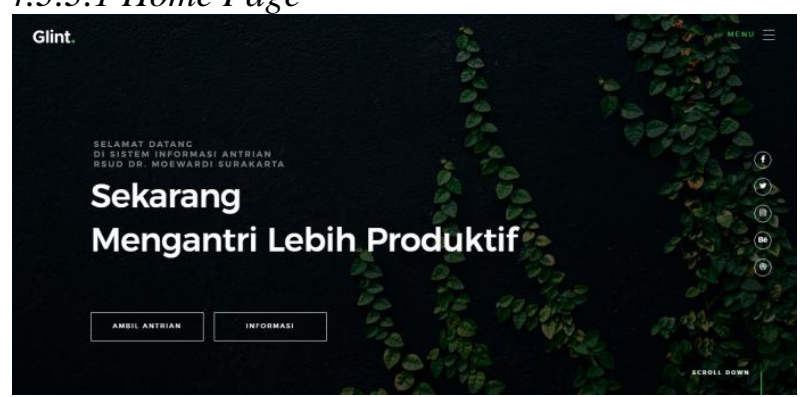

Fig 7 : Home Page

The fig. 7 is an home page of the system. Customer can know the information about the system here.

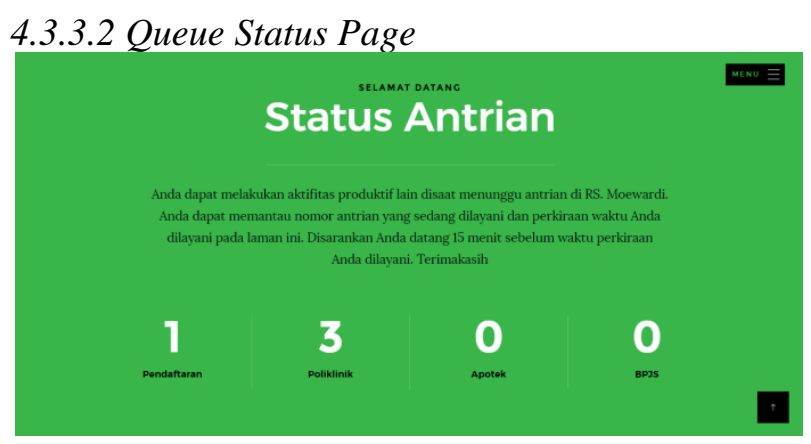

Fig 8 : Queue Status Page

Fig. 8 is queue status page. Customer can monitor status of queue on this page. 


\subsubsection{Detail Queue Status Page}

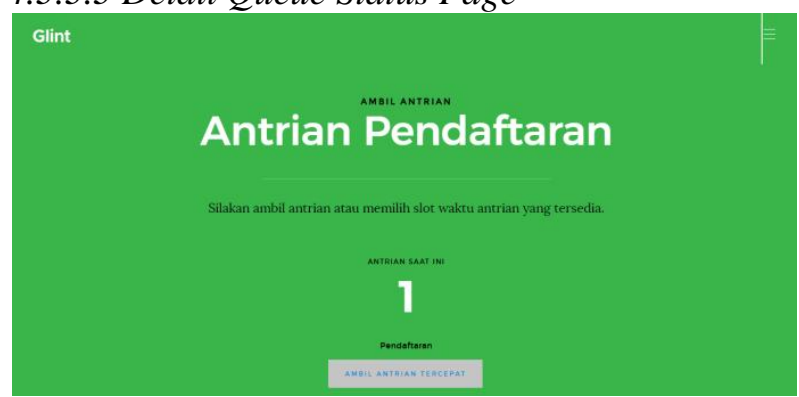

Fig 9 : Detail Queue Status Page

Fig. 9 is detail queue status page. The next step from queue status page. Customer can monitor status of type of queue.

\subsubsection{Queue Slot Page}

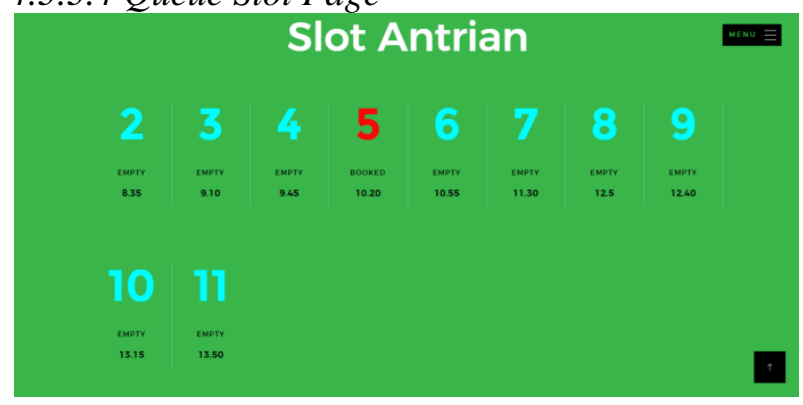

Fig 10 : Queue Slot Page

Fig. 10 is queue slot page. Customer can see and choose slot time.

\subsubsection{Admin Queue Status Page}

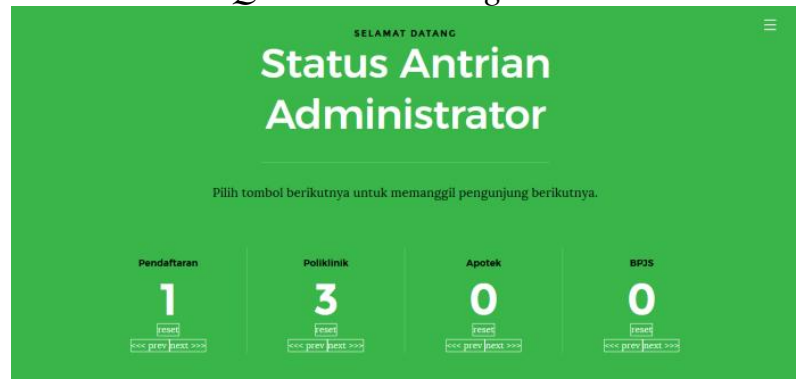

Fig 11 : Admin Queue Status Page

Fig. 11 is administrator queue status page. Admin can monitor and manage queue from this page.

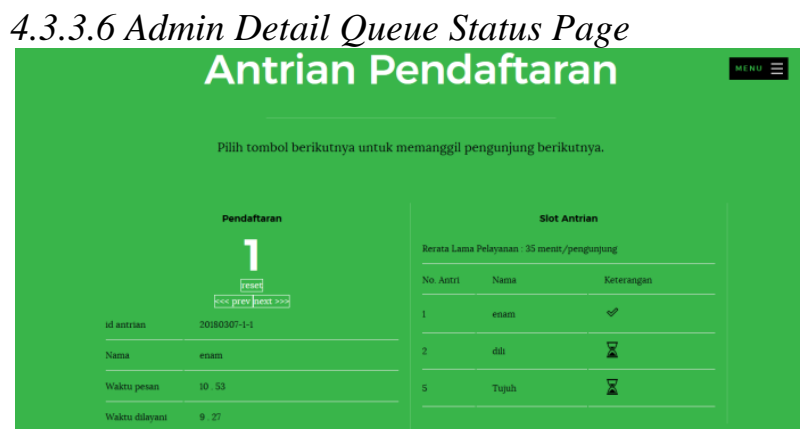

Fig 12 : Detail Admin Queue Status Page

Fig. 12 is detail of administrator queue status page. Admin can monitor and manage the detail of queue.

\section{EXPERIMENTAL RESULT}

\subsection{Information System Framework}

The data of queue in hospital includes arrival time, time served how long the customer served is stored in database on cloud and analyzed with FCFS+PQ. Then, the data before and after the system applied is compared to show the result of FCFS+PQ.

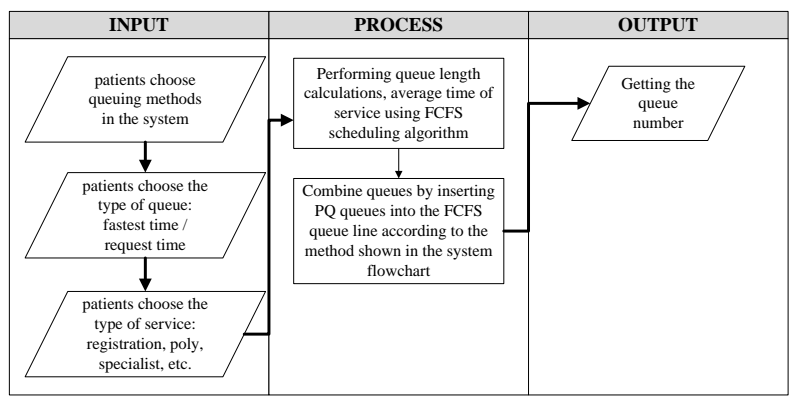

Fig 13 : Information System Framework

\subsection{Implementation and Result}

After implementation, The data shown in table 3

Table 3. Queue Data after Implementation

\begin{tabular}{|l|l|l|l|}
\hline $\begin{array}{l}\text { Customer } \\
\text { Number }\end{array}$ & $\begin{array}{l}\text { Arrival } \\
\text { Time }\end{array}$ & $\begin{array}{l}\text { Start Time } \\
\text { Served }\end{array}$ & $\begin{array}{l}\text { Finished } \\
\text { Time Served }\end{array}$ \\
\hline 1 & 07.30 & 08.00 & 08.10 \\
\hline 2 & 07.35 & 08.10 & 08.22 \\
\hline 3 & 08.05 & 08.22 & 08.34 \\
\hline 4 & 08.20 & 08.35 & 08.45 \\
\hline 5 & 08.30 & 08.45 & 08.53 \\
\hline 6 & 08.50 & 08.55 & 09.05 \\
\hline 7 & 08.45 & 09.05 & 09.15 \\
\hline 8 & 09.00 & 09.15 & 09.25 \\
\hline 9 & 09.10 & 09.25 & 09.35 \\
\hline 10 & 09.30 & 09.35 & 09.47 \\
\hline 11 & 09.30 & 09.48 & 09.58 \\
\hline 12 & 09.30 & 09.58 & 10.10 \\
\hline 13 & 09.45 & 10.10 & 10.20 \\
\hline 14 & 10.00 & 10.20 & 10.40 \\
\hline 15 & 10.30 & 10.40 & 11.00 \\
\hline 16 & 10.45 & 11.00 & 11.15 \\
\hline 17 & 11.00 & 11.15 & 11.30 \\
\hline 18 & 11.00 & 11.30 & 11.45 \\
\hline 19 & 12.30 & 13.00 & 13.15 \\
\hline 20 & 13.00 & 13.15 & 13.25 \\
\hline 21 & 13.20 & 13.25 & 13.35 \\
\hline 22 & 13.20 & 13.35 & 13.45 \\
\hline 23 & 13.30 & 13.45 & 14.00 \\
\hline
\end{tabular}

Then, analyzing Kendall Notation 
5.2.1 Shows The Variable of Data Type

Counting customer arrivals:

$$
\begin{aligned}
\lambda & =\frac{1}{T 1 / N} \\
\lambda & =\frac{1}{360 / 16.65} \\
\lambda & =\frac{1}{21.62} \\
\lambda & =0.046
\end{aligned}
$$

Calculating service levels:

$$
\begin{aligned}
\mu & =\frac{1}{T 2 / N} \\
\mu & =\frac{1}{281 / 23} \\
\mu & =\frac{1}{12.217} \\
\mu & =0.08
\end{aligned}
$$

5.2.2 Determines The Value of Unemployment Opportunity $\left(P_{0}\right)$

$$
\begin{aligned}
& P_{0}=\left(\sum_{n=0}^{c=1} \frac{\left(\frac{\lambda}{\mu}\right)^{n}}{n !}+\frac{\left(\frac{\lambda}{\mu}\right)^{c}}{c !\left(1-\left(\frac{\lambda}{c} . \mu\right)\right.}\right)^{-1} \\
& P_{0}=\left(\frac{\left(\frac{0.046}{0.08}\right)^{0}}{0 !}+\left(\frac{\left(\frac{0.046}{0.08}\right)^{1}}{1 !\left(1-\frac{0.046}{1(0.08)}\right)}\right)^{-1}\right. \\
& P_{0}=\left(\frac{1}{1}+\frac{0.575}{1 .(1-0.575)}\right)^{-1} \\
& P_{0}=\left(1+\frac{0.575}{1(0.425)}\right)^{-1} \\
& P_{0}=\left(1+\frac{0.575}{0.425}\right)^{-1} \\
& P_{0}=(1+1.35)^{-1} \\
& P_{0}=(2.35)^{-1} \\
& P_{0}=\frac{1}{2.35} \\
& P_{0}=0.425 \text { or } 42.5 \%
\end{aligned}
$$

\subsubsection{Determining Average Number of Customers} in Queue

$$
\begin{aligned}
L_{q} & =\frac{\left(\frac{\lambda}{\mu}\right)^{c} \cdot\left(\frac{\lambda}{c \cdot \mu}\right)}{c !\left(1-\left(\frac{\lambda}{c \cdot \mu}\right)\right)^{2}} P_{0} \\
L_{q} & =\frac{\left(\frac{0.046}{0.08}\right)^{1} \cdot\left(\frac{0.046}{1 \cdot(0.08)}\right)}{1 !\left(1-\left(\frac{0.046}{1 \cdot(0.08)}\right)\right)^{2}} \cdot(0.5) \\
L_{q} & =\frac{(0.575) \cdot(0.575)}{1 .(1-(0.575))^{2}} \cdot(0 \\
L_{q} & =\frac{0.33}{(0.425)^{2} \cdot(0.425)} \\
L_{q} & =\frac{0.33}{0.18} \cdot(0.425) \\
L_{q} & =(1.83) \cdot(0.425) \\
L_{q} & =0.78
\end{aligned}
$$

The value of $\mathrm{Lq}$ is 0.78 , rounded to 1 . So the average number of customers in the queue is 1 customers in the queue.
5.2.4 Determining Average Number of Customers in The System

$$
\begin{aligned}
& L_{s}=L_{q}+\frac{\lambda}{\mu} \\
& L_{s}=0.78+\frac{0.046}{0.08} \\
& L_{s}=0.78+0.575 \\
& L_{s}=1.35
\end{aligned}
$$

The value of Ls is 1.35 , it beetwen 1 and 2. So the average number of customers in the system is 1 untill 2 customers in the system.

\subsubsection{Determining Average Time Customer in} Quеие

$$
\begin{aligned}
& W_{q}=\frac{L_{q}}{\lambda} \\
& W_{q}=\frac{0.78}{0.046} \\
& W_{q}=16.96
\end{aligned}
$$

The $\mathrm{Wq}$ value is 16.96 , rounded to 17 . So the average customer time in the queue is 17 minutes / customer.

\subsubsection{Determining Average Time Customer in} System

$$
\begin{aligned}
& W_{s}=W_{q}+\frac{1}{\mu} \\
& W_{s}=16.96+\frac{1}{0.08} \\
& W_{s}=16.96+12.5 \\
& W_{s}=29.46
\end{aligned}
$$

The value of Ws is 29.46 . So the average customer time in the system is 29 minutes / customer.

\section{CONCLUCION}

Generally, FCFS is used for almost all types of queues for human services. FCFS will still be a heap of customers if there are many customers who come and no server is ready yet. Now customers want to queue with no waiting, or at least with the minimum waiting time. The solution of the problem is monitoring the queue with the online system. The online system is still not enough, the customers want to order a certain time to be served, the solution is with the time request. Then FCFS is combined with PQ. In this case, research in the hospital queue. Before using this system the patient can queue for up to 2 hours, after using this system patient waiting time on average reduced to 30 minutes. Another advantage is the hospital has experienced employee performance efficiency because there is no idle time for employees and there are not many queues at the service place.

\section{REFERENCES}

[1] Takagi, H., 2014, From Computer Science to Service Science: Queues with Human Customers And Servers, Faculty of Engineering, Information and Sistems, University of Tsukuba, Tsukuba Science City, Ibaraki 305-8573, Japan.

[2] Gross, D., and Harris, C., 1998, Fundamental of Queuing Theory, Third Edition, USA: MC Graw Hill, pp. 2830.

[3] Platz, T., and Osterdal, L., 2015, The Curse of The Firstin First-out Queue Discipline, University of Southern Denmark, pp. 80-85. 
[4] Pinedo, M., 2016, Schedulling: Theory, Algorithms, and Sistem. NYU Stern School of Business, New York, pp. 57-58.

[5] Erl, T., and Puttini, R., 2013, Cloud Computing: concepts, technology and Architecture, Prentice Hall.

[6] Hao, T., and Yifei, T., 2011, Study on Queuing Sistem Optimization of Bank Based on BPR, Nanjing University of Science and Technology, School of Mechanical Engineering 402, 210094 Nanjing, Republic of China.

[7] Taufemback, C., dan Da Silva, S., 2012, Queuing Theory Applied to The Optimal Management of Bank Excess Reserves. Program in Economics, Federal University of Santa Catarina, Florianopolis SC88049-970, Brazil.

[8] Walraevens, J., dan Bruneel, H., 2017, Delay analysis of multiclass queues with correlated train arrivals and a hybrid priority/FIFO scheduling discipline. Department of Telecommunication and Information Processing, Ghent University, Belgium
[9] Pinedo, M., 2016, Schedulling: Theory, Algorithms, and Sistem. NYU Stern School of Business, New York, pp. 87-90.

[10] Aminudin, 2005, Principal of Research Operation, Jakarta : Erlangga.

[11]Platz, T., and Osterdal, L., 2015, The Curse of The Firstin First-out Queue Discipline, University of Southern Denmark, 92-95.

[12] Gross, D., and Harris, C., 1998, Fundamental of Queuing Theory, Third Edition, USA: MC Graw Hill, 101-110.

[13] Gross, D., and Harris, C., 1998, Fundamental of Queuing Theory, Third Edition, USA: MC Graw Hill, 115-120.

[14] Arina, S., and Harahap, R., 2014, Analysis of Queue Service System in PT BNI, Department of Mathematics , Faculty of Mathematics and Natural Sciences , University of Sumatera Utara.

[15] Erl, T., and Puttini, R., 2013, Cloud Computing. concepts, technology and Architecture, Prentice Hall. 